JURNAL ILMIAH KOMPUTER GRAFIS, Vol.13, No.1, Juli 2020, pp. 9 - 15

p-ISSN : 1979-0414(print)

e-ISSN : 2621-6256 (online)

http://journal.stekom.ac.id/index.php/pixel

- page 9

\title{
Implementation of Distance-Angle Signature as Object Shape Identifier for Digital Images
}

\author{
Andika Setiawan ${ }^{1}$, Rajif Agung Yunmar ${ }^{2}$ \\ ${ }^{1,2}$ Institut Teknologi Sumatera \\ JI. TerusanRyacudu, Jati Agung, Lampung Selatan, (0721) 8030188, e-mail: andika.setiawan@if.itera.ac.id
}

\begin{tabular}{ll}
\hline ARTICLE INFO & ABSTRACT \\
\hline Article history: & $\begin{array}{l}\text { The transformation of objects in computer } \\
\text { graphics is very closely related to the factor of }\end{array}$ \\
$\begin{array}{l}\text { Received } 30 \text { Mei } 2020 \\
\text { Received in revised form } 2 \text { Juni } 2020\end{array}$ & $\begin{array}{l}\text { scale and rotation. Both are often a challenge in } \\
\text { the introduction of objects through numerical } \\
\text { Accepted } 10 \text { Juli } 2020\end{array}$ \\
features in digital images. Feature processing \\
techniques that can overcome these problems \\
such as Distance - Angle signature that is \\
invariant to the scale and rotation factor. From \\
the results of experiments conducted on 5 types \\
of geometric shape images which amounted to \\
15 data with scale and rotation factors obtained \\
the results that the Angle Signature can be \\
applied well on all data. Inequality in the \\
signature plot images obtained is due to the \\
lighting conditions and background objects that \\
are not uniform, which occurs in the image of a \\
circle for all three types.
\end{tabular}

Keywords: computer graphics, digital images, feature, signature, geometric

\section{Introduction}

In computer graphics some general concepts of object transformation that are very often used include scale and rotation factors[1]. The transformation process is usually associated with 2dimensional objects on a flat plane in the form of digital images. To be able to identify an object in the image, it is necessary to do a general processing process in the form of segregation and feature extraction[2]. Numerical features become very important because they can be used as an identifier that distinguishes one object from another[3]. The process of identifying objects through numerical features on the transformation process in the form of scale and rotation greatly influences the recognition results of an image [4]. In addition, mismatches of features extracted by the treatment of objects can cause recognition errors.

One feature processing technique that can prevent these errors is the Distance - Angle signature. The signature feature can distinguish well from object shapes applying the difference value and shape number to the origin signature of the object being tested by normalizing and equating the same range of values for the amplitude functions [5]. This research measures several geometric objects in 3 forms, including transformation factors that can affect the object identification process. The expected result is a graphical display that becomes an identifier for the use of the distance-angle signature feature that is invariant to the scale and rotation factor in 2-dimensional object images. 


\section{Research Method}

This research was carried out in stages until the signature plot was formed from numbers of feature points extracted. The stages in the form of the method applied can be seen in Figure 1.

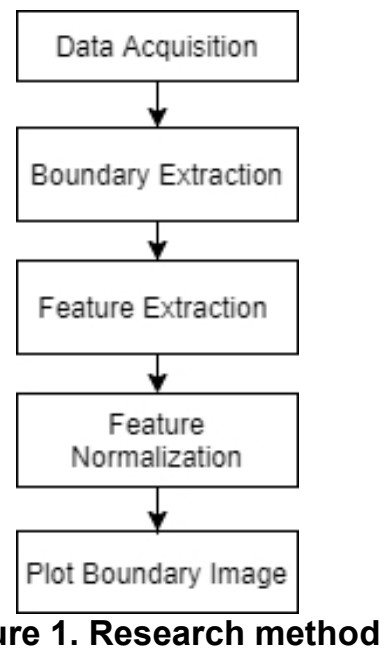

\subsection{Data Acquisition}

This initial stage is done by taking an object image from several shapes of flat shape. Objects are captured using an 8 mega pixel resolution digital camera with varying lighting conditions, background colors, and color objects. The shapes of the flat shapes acquired are square, rectangular, triangular, circular and elliptical. The five acquired objects consist of 3 types of shapes, including normal shapes, scaled (reduced) shapes, and rotated shapes. Before entering the next stage, all image data is resized to be smaller to improve processing and ease computing.

\subsection{Boundary Extraction}

The next step is to extract the boundary edges of the object. The extraction process involves several activities whose stages are shown in Figure 2.

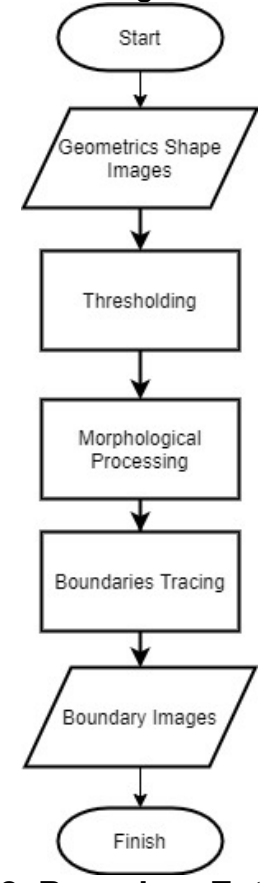

Figure2. Boundary Extraction Process 
The input image processed is $336 \times 448$ pixels. The input image is then subjected to a thresholding process that converts the input image into a binary format (black and white image)[6]. The image of the thresholding process output is subject to a morphological operation process if the process output does not match the expected results, for example it includes non-object parts due to noise and shadows in the object image. Morphological operations performed are erosion and dilation of objects in binary images. The final process of this stage is the boundary tracing stage with the edge output of an object with a size of 1 pixel in white with a black background image output.

\subsection{Feature Extraction}

Feature extraction with Distance Angle Signature is based on external boundaries and corespondingr $(\theta)$ signatures[7]. This feature rating is based on a 360 degrees angle. Representation of angle signature features are shown in Figure 3.

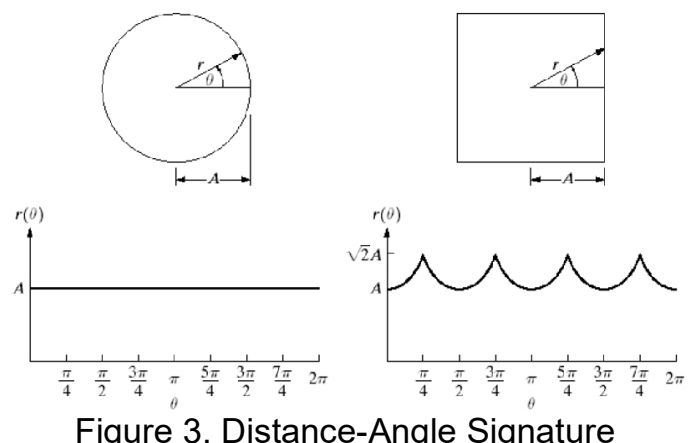

The binary image created in the form of an edge object is searched for the centroid value first. Centroid value is obtained by finding rounding of the sum of the pixel coordinate values of the bed based on $x$ which is then divided by the boundary (edge) to get the centroid coordinates $\mathrm{x} 0$ and looking for rounding from the sum of the pixel coordinate frame divided by the limit used to get the centroid coordinates y0.

The distance value is calculated from the difference between the object's boundary distance to the centroid coordinates. The greater the distance between the centroid and the boundary of the object, the greater the distance value. The distance value is calculated by the Rho function for each Theta object[7]. Theta value used in this experiment is 15 degrees, so that the total angular distance of the signature changes to 24 variables which at the same time represent an angle of 1 full rotation of an object.

\subsection{Feature Normalization}

Feature normalization process aims to eliminate the range of values that are too far between the value of features of an object and reduce computation. Normalization technique used in this study is min-max normalization because it has minimum misclassification error[8].The image that has been taken by the signature feature needs to be normalized because each object must be different from the object in the image that is used as a reference, resulting in the signature plot will be different even though the objects in the image are the same. To say there is a scaling on the object, it is necessary to normalize, namely the min-max value of the distance ( $r$ ) with the formula (1).

$$
\mathrm{r}_{\mathrm{norm}}=\frac{\mathrm{r}_{1}-\min (\mathrm{r})}{\max (\mathrm{r})-\min \left(\mathrm{r}_{-}^{2}\right.}
$$

Distance normalization values will be in the range 0 to $1[2]$. While to overcome the rotation, it is necessary to find the starting point value with the lowest $r$ norm value, or it can be written with the formula (2).

$$
\text { starting poin }=\min \left(r_{\text {nom }}\right)
$$




\subsection{Signature Plot}

This stage displays the image of the results of the features that have been normalized to form graphical $x$ and $y$ axis. The value of the feature will be retouched to obtain a new signature value that is uniform in terms of the starting point and by not changing the amplitude of the signature origin image. The result value of the new signature will then be extracted as a feature of the image object in the form of a row of representation values of the object represented by its amplitude point. The y-axis represents scale, while the $x$-axis represents the number of extraction points, 24 of which represent each point and represent 15 degrees from a total of 360 degrees.

\section{Results and Analysis}

The research method in the form of stages has gotten results in each phase. From numbers of 5 main stages that have been carried out, the results are described as 3 main stages, because the process of data acquisition and edge extraction of objects is grouped into a single unit.

\subsection{Data Acquisition and Boundary Extraction}

Geometric object image data collected consists of 5 shapes, including triangles, squares, rectangles, circles and ellipses. Each object consists of 3 types of capture, including normal objects, scaling objects, and rotational effects objects. Boundary image is the edge of the object image from the results of thresholding and morphological operations in the form of a border of each object. These margins will be numeric features which will be processed at the feature extraction stage. The results of data acquisition and triangle object boundary can be seen in Table 1, the results of the acquisition and boundary of triangle, square, rectangular, circle and ellipse objects can be selected respectively in Table 1, Table 2, Table 3, Table 4, and Table 5.

Table 1. Results of triangleobjects

\begin{tabular}{|c|c|c|}
\hline $\begin{array}{c}\text { Image } \\
\text { Name }\end{array}$ & Acquisition Image & Boundary Image \\
\hline $\begin{array}{c}\text { Triangle } \\
\text { (1).jpg }\end{array}$ & & \\
\hline $\begin{array}{c}\text { Triangle } \\
\text { (2).jpg }\end{array}$ & & \\
\hline $\begin{array}{c}\text { Triangle } \\
\text { (3).jpg }\end{array}$ & & \\
\hline
\end{tabular}

Table 3. Results of square objects

\begin{tabular}{|c|c|c|}
\hline $\begin{array}{c}\text { Image } \\
\text { Name }\end{array}$ & Acquisition Image & Boundary Image \\
\hline $\begin{array}{c}\text { Square } \\
\text { (1).jpg }\end{array}$ & & \\
\hline
\end{tabular}

Table 2. Results of rectangle objects

\begin{tabular}{|c|c|c|}
\hline $\begin{array}{c}\text { Image } \\
\text { Name }\end{array}$ & Acquisition Image & Boundary Image \\
\hline $\begin{array}{c}\text { Rectangle } \\
\text { (1).jpg }\end{array}$ & & \\
\hline $\begin{array}{c}\text { Rectangle } \\
\text { (2).jpg }\end{array}$ & & \\
\hline $\begin{array}{c}\text { Rectangle } \\
\text { (3).jpg }\end{array}$ & & \\
\hline
\end{tabular}

Table 4. Results of circle objects

\begin{tabular}{|c|c|c|}
\hline $\begin{array}{l}\text { Image } \\
\text { Name }\end{array}$ & Acquisition Image & Boundary Image \\
\hline $\begin{array}{c}\text { Circle } \\
\text { (1).jpg }\end{array}$ & & \\
\hline
\end{tabular}

JURNAL ILMIAH KOMPUTER GRAFIS Vol. 13, No. 1, Juli2020 : 9-15 


\begin{tabular}{|c|c|c|}
\hline $\begin{array}{c}\text { Image } \\
\text { Name }\end{array}$ & Acquisition Image & Boundary Image \\
\hline $\begin{array}{c}\text { Square } \\
\text { (2).jpg }\end{array}$ & & \\
\hline $\begin{array}{l}\text { Square } \\
\text { (3).jpg }\end{array}$ & & \\
\hline
\end{tabular}

\begin{tabular}{|c|c|c|}
\hline $\begin{array}{l}\text { Image } \\
\text { Name }\end{array}$ & Acquisition Image & Boundary Image \\
\hline $\begin{array}{c}\text { Circle } \\
\text { (2).jpg }\end{array}$ & & \\
\hline & & \\
\hline Circle & & \\
(3).jpg & & \\
\hline
\end{tabular}

Table 5. Result of ellipse objects

\begin{tabular}{|l|l|l|}
\hline $\begin{array}{l}\text { Image } \\
\text { Name }\end{array}$ & Acquisition Image & Boundary Image \\
\hline $\begin{array}{l}\text { Ellipse } \\
\text { (1).jpg }\end{array}$ & & \\
\hline $\begin{array}{l}\text { Ellipse } \\
\text { (2).jpg }\end{array}$ & & \\
\hline
\end{tabular}

\subsection{Feature Extraction and Normalization}

This stage takes the signature value followed by a normalization process that shortens the range of features. The normalization process is done first looking for the value of the edge coordinates of the difference values of the edge of the object in accordance with the smallest to largest value on a scale of 0 to 1 . Each object image produces 24 feature points as their respective identifiers. Some features are point amplitude signatures of theta value of 15 degrees per point. The results of the normalized features of 15 objects can be seen in Table 6 .

Table6. Results of the normalized features

\begin{tabular}{|c|c|c|c|} 
Object Name & $\begin{array}{c}\text { Normalized feature } \\
\text { of normal form }\end{array}$ & $\begin{array}{c}\text { Normalized feature } \\
\text { of scale form }\end{array}$ & $\begin{array}{c}\text { Normalized feature } \\
\text { of rotational form }\end{array}$ \\
\hline
\end{tabular}


p-ISSN : 1979-0414 e-ISSN : 2621-6256

\begin{tabular}{|c|c|c|c|}
\hline Object Name & $\begin{array}{c}\text { Normalized feature } \\
\text { of normal form }\end{array}$ & $\begin{array}{l}\text { Normalized feature } \\
\text { of scale form }\end{array}$ & $\begin{array}{l}\text { Normalized feature } \\
\text { of rotational form }\end{array}$ \\
\hline Rectangle & $\begin{array}{c}\text { > FiturSignature } \\
\text { nilaisignature = } \\
0 \\
0.2787 \\
0.4246 \\
0.5075 \\
0.5281 \\
0.6127 \\
0.7480 \\
1.0000 \\
0.5023 \\
0.3601 \\
0.5473 \\
0.6605 \\
0.4862 \\
0.0364 \\
0.2952 \\
0.4237 \\
0.5187 \\
0.6136 \\
0.7417 \\
1.0000 \\
0.5325 \\
0.3639 \\
0.5058 \\
0.6453 \\
0.5921\end{array}$ & $\begin{array}{c}\text { > FiturSignature } \\
\text { nilaisignature }= \\
0 \\
0.2952 \\
0.4294 \\
0.4912 \\
0.5335 \\
0.6210 \\
0.7426 \\
1.0000 \\
0.4623 \\
0.3740 \\
0.5396 \\
0.6595 \\
0.5255 \\
0.0474 \\
0.3075 \\
0.4346 \\
0.5245 \\
0.6141 \\
0.7406 \\
1.0000 \\
0.5406 \\
0.3625 \\
0.5245 \\
0.6382 \\
0.6332\end{array}$ & $\begin{array}{c}\text { 》 FiturSignature } \\
\text { nilaisignature }= \\
0 \\
0.2224 \\
0.3641 \\
0.4753 \\
0.5891 \\
0.7724 \\
1.0000 \\
0.1391 \\
0.3277 \\
0.4688 \\
0.6676 \\
0.3677 \\
0.0748 \\
0.0217 \\
0.2240 \\
0.3641 \\
0.4674 \\
0.7586 \\
0.6555 \\
0.8951 \\
0.1295 \\
0.3510 \\
0.4921 \\
0.6840 \\
0.0054\end{array}$ \\
\hline Square & $\begin{array}{c}\text { > FiturSignature } \\
\text { nilaisignature = } \\
0 \\
0.2719 \\
0.4657 \\
0.6944 \\
0.9241 \\
0.5006 \\
0.0464 \\
0.2928 \\
0.4621 \\
0.5083 \\
0.6802 \\
0.9557 \\
0.5469 \\
0.0074 \\
0.2679 \\
0.5077 \\
0.6840 \\
0.9354 \\
0.3951 \\
0.0188 \\
0.2994 \\
0.4866 \\
0.6735 \\
1.0000 \\
0.4710\end{array}$ & $\begin{array}{c}\text { > FiturSignature } \\
\text { nilaisignature }= \\
0 \\
0.3164 \\
0.5007 \\
0.6841 \\
0.9735 \\
0.5024 \\
0.0437 \\
0.3060 \\
0.4748 \\
0.5221 \\
0.6509 \\
0.9735 \\
0.5493 \\
0.0278 \\
0.2871 \\
0.5217 \\
0.6925 \\
0.9722 \\
0.3551 \\
0.0737 \\
0.3164 \\
0.5007 \\
0.6841 \\
1.0000 \\
0.4758\end{array}$ & $\begin{array}{l}\text { > FiturSignature } \\
\text { nilaisignature }= \\
0 \\
0 \\
0.2325 \\
0.3769 \\
0.5108 \\
0.7125 \\
0.6645 \\
0.2859 \\
0.0460 \\
0.2458 \\
0.3995 \\
0.5108 \\
1.0000 \\
0.2537 \\
0.0312 \\
0.2381 \\
0.3995 \\
0.5123 \\
0.7016 \\
0.5412 \\
0.0271 \\
0.2514 \\
0.3867 \\
0.5328 \\
0.7005 \\
0.6710\end{array}$ \\
\hline Triangle & $\begin{array}{c}\text { >> FiturSignature } \\
\text { nilaisignature = } \\
0 \\
0.3066 \\
0.4368 \\
0.4837 \\
0.5274 \\
0.5358 \\
0.5733 \\
0.6282 \\
0.7239 \\
1.0000 \\
0.2313 \\
0.4133 \\
0.4099 \\
0.4650 \\
0.5374 \\
0.5806 \\
0.6694 \\
0.5165 \\
0.3928 \\
0.4726 \\
0.5263 \\
0.5841 \\
0.6620 \\
0.7959 \\
0.8049\end{array}$ & $\begin{array}{c}\text { >> FiturSignature } \\
\text { nilaisignature = } \\
0 \\
0.2751 \\
0.3974 \\
0.4505 \\
0.4827 \\
0.4913 \\
0.5250 \\
0.5777 \\
0.6734 \\
1.0000 \\
0.1361 \\
0.3992 \\
0.3598 \\
0.4341 \\
0.4956 \\
0.5398 \\
0.6134 \\
0.4745 \\
0.3489 \\
0.4357 \\
0.4789 \\
0.5395 \\
0.6149 \\
0.7627 \\
0.6492\end{array}$ & $\begin{array}{c}\text { >> FiturSignature } \\
\text { nilaisignature = } \\
0 \\
0.4244 \\
0.4469 \\
0.4482 \\
0.4778 \\
0.5190 \\
0.5426 \\
0.6104 \\
0.5743 \\
0.7255 \\
1.0000 \\
0.1810 \\
0.3707 \\
0.4581 \\
0.5040 \\
0.5464 \\
0.5919 \\
0.6859 \\
0.4326 \\
0.4321 \\
0.4966 \\
0.5413 \\
0.5884 \\
0.6806 \\
0.7974\end{array}$ \\
\hline
\end{tabular}

JURNAL ILMIAH KOMPUTER GRAFIS Vol. 13, No. 1, Juli2020 : 9-15 


\begin{tabular}{|c|c|c|c|}
\hline Object Name & $\begin{array}{c}\text { Normalized feature } \\
\text { of normal form }\end{array}$ & $\begin{array}{c}\text { Normalized feature } \\
\text { of scale form }\end{array}$ & $\begin{array}{c}\text { Normalized feature } \\
\text { of rotational form }\end{array}$ \\
\hline Circle & $\begin{array}{l}\text { >> FiturSignature } \\
\text { nilaisignature }= \\
0 \\
0.9735 \\
0.6225 \\
0.8886 \\
0.2260 \\
0.9388 \\
0.7749 \\
0.3864 \\
0.6216 \\
0.4180 \\
0.5179 \\
0.3630 \\
0.4416 \\
0.0605 \\
0.7994 \\
0.3850 \\
0.7369 \\
0.4731 \\
0.6488 \\
1.0000 \\
0.6006 \\
0.8475 \\
0.4180 \\
0.2260 \\
0.6549\end{array}$ & $\begin{array}{c}\text { >> FiturSignature } \\
\text { nilaisignature }= \\
0 \\
0.9014 \\
1.0000 \\
0.5728 \\
0.6465 \\
0.5107 \\
0.7027 \\
0.4151 \\
0.7836 \\
0.2659 \\
0.7782 \\
0.4015 \\
0.7698 \\
0.8488 \\
0.5671 \\
0.5728 \\
0.6465 \\
0.5107 \\
0.7027 \\
0.5581 \\
0.6787 \\
0.5671 \\
0.5728 \\
0.6465 \\
0.5107\end{array}$ & $\begin{array}{c}\text { > FiturSignature } \\
\text { nilaisignature = } \\
0 \\
0.3960 \\
0.5262 \\
0.0427 \\
0.3857 \\
0.7299 \\
0.4055 \\
0.4010 \\
0.4647 \\
0.2089 \\
0.2412 \\
0.5068 \\
0.3733 \\
0.1620 \\
0.2340 \\
0.3348 \\
0.1389 \\
0.4810 \\
1.0000 \\
0.4248 \\
0.4002 \\
0.1761 \\
0.2089 \\
0.3879 \\
0.3733\end{array}$ \\
\hline 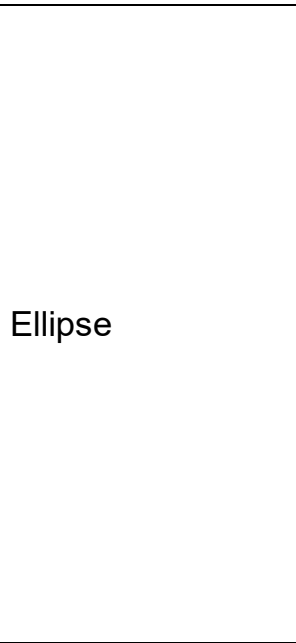 & $\begin{array}{c}\text { > FiturSignature } \\
\\
\text { nilaisignature = } \\
0 \\
0.0428 \\
0.2583 \\
0.3329 \\
0.4935 \\
0.4786 \\
0.6169 \\
0.7403 \\
0.9257 \\
0.9599 \\
0.9348 \\
0.4920 \\
0.1424 \\
0.0327 \\
0.1194 \\
0.2360 \\
0.3291 \\
0.4979 \\
0.5520 \\
0.6907 \\
0.8789 \\
0.9021 \\
1.0000 \\
0.5192 \\
0.2044\end{array}$ & $\begin{array}{c}\text { > FiturSignature } \\
\text { nilaisignature = } \\
0 \\
0.2958 \\
0.3317 \\
0.4794 \\
0.4912 \\
0.6483 \\
0.7785 \\
0.9303 \\
0.9965 \\
0.8855 \\
0.4738 \\
0.1099 \\
0.0093 \\
0.1267 \\
0.2464 \\
0.3711 \\
0.5054 \\
0.6061 \\
0.7460 \\
0.8809 \\
1.0000 \\
0.9698 \\
0.4703 \\
0.1211 \\
0.0405\end{array}$ & $\begin{array}{c}\text { >> FiturSignature } \\
\text { nilaisignature = } \\
0 \\
0.1075 \\
0.2406 \\
0.3560 \\
0.4652 \\
0.6020 \\
0.7290 \\
0.8962 \\
1.0000 \\
0.7568 \\
0.3762 \\
0.0656 \\
0.1586 \\
0.2557 \\
0.1506 \\
0.2561 \\
0.379 \\
0.5264 \\
0.7987 \\
0.6464 \\
0.8699 \\
0.9733 \\
0.8129 \\
0.3985 \\
0.0091\end{array}$ \\
\hline
\end{tabular}

\subsection{Signature Plot}

The normalized features of the 15 objects that have been obtained are then plotted into signature images that characterize each object. The plot image is the result of the features displayed on the $x$-axis expressing the number of feature points, while the $y$-axis represents the scale of the features from 0 to 1 . The signature results of 15 images from 5 types of objects can be seen in Table 7.Row (1) in the table shows the normal form, row (2) shows the scaled form, while row (3) shows the rotational form.

Table 7. Signature plot of each object

\begin{tabular}{|l|c|c|c|c|c|c|}
\hline No. & Triangle & Square & Rectangle & Circle & Ellipse \\
\hline \multirow{3}{*}{$(1)$} & & & & & &
\end{tabular}




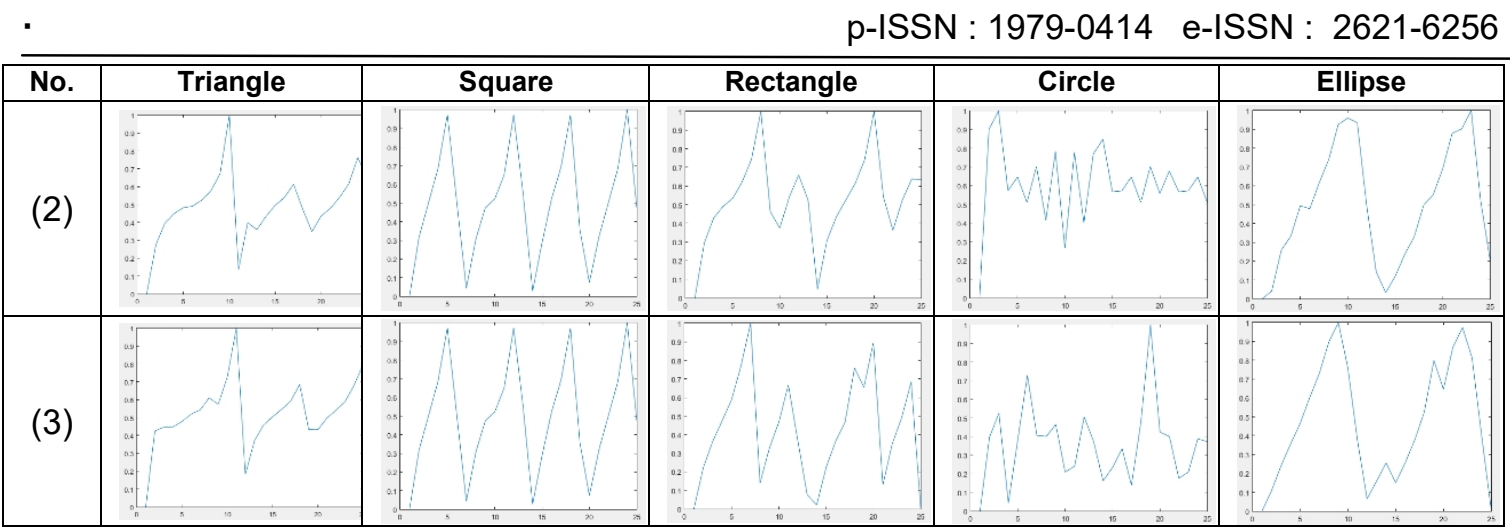

\section{Conclusion}

Experiments have been carried out for 15 types of objects from each of 3 types of objects, namely rectangular, square, triangle, circle and ellipse. The signature plot obtained from each object shows that the signature shape on the triangular, square, ellipse, and rectangular objects looks similar to the four image shapes. As with the shape on the circle object that looks a little different. The difference occurs because of differences in the results of segmentation and morphological operations that have been carried out. The segmented circle object has a different lighting and background color to other objects so that it affects the signature results of each type of shape. In addition, the plot obtained shows that the value and shape of the signature does not have much effect on the scaling, but not on the rotated form, because it shows a slightly different signature form compared to the normal form and the scaling form. The reshaped plot image also shows that the angle-signature feature of an object can be used as an identifier to describe the shape of the object through the axis of the cartesian coordinates in a 2-dimensional image.

\section{References}

[1] R. Goldman, An Integrated Introduction to Computer Graphics and Geometric Modeling, Boca Raton: CRC Press, 2009.

[2] A. Setiawan, A. Harjoko, T. Ratnaninghsih, E. Suryani, W. Wiharto and W. S. Palgunadi, "Classification of Cell Types In Acute Myeloid Leukemia (AML) of M4, M5 and M7 Subtypes With Support Vector Machine Classifier," in International Conference on Information and Communications Technology (ICOIACT), Yogyakarta, 2018.

[3] R. Jana, R. Saha and D. Datta, "Offline Signature Verification using Euclidian Distance," (IJCSIT) International Journal of Computer Science and Information Technologies, vol. 5, no. 1, pp. 707-710, 2014.

[4] R. A. Yunmar and A. Harjoko, "Sistem Identifikasi Relief pada Situs Bersejarah Menggunakan Perangkat Mobile Android (Studi Kasus Candi Borobudur)," IJCCS (Indonesian Journal of Computing and Cybernetics Systems), vol. 8, no. 2, pp. 133-144, 2014.

[5] H. Muhamad, M. N. Firadus, B. P. Pamungkas and S. Usman, "Leaf morphological feature extraction based on K-Nearest Neighbor," in 2018 International Conference on Information and Communications Technology, ICOIACT 2018, Yogyakarta, 2018.

[6] Y. D. Pristanti and P. Mudjirahardjo, "Identifikasi Tanda Tangan dengan Ekstraksi Ciri GLCM dan LBP," Jurnal EECCIS, vol. 13, no. 1, pp. 6-10, 2019.

[7] R. C. Gonzalez and R. E. Woods, Digital Image Processing (3rd Edition), New Jersey: Prentice Hall, 2008.

[8] C. Saranya and G. Manikandan, "A study on normalization techniques for privacy preserving data mining," International Journal of Engineering and Technology, vol. 5, no. 3, pp. 27012704, 2013.

JURNAL ILMIAH KOMPUTER GRAFIS Vol. 13, No. 1, Juli2020 : 9 - 15 